\title{
(2) astum \\ Diabetes mellitus and carotid artery plaques exhibiting high-intensity signals on MR angiography are related to increased platelet reactivity after carotid artery stenting
}

\author{
Masanori Tsujimoto, Yukiko Enomoto, Jouji Kokuzawa, Toru Iwama
}

Department of Neurosurgery, Gifu University Graduate School of Medicine, Gifu, Japan

Correspondence to Dr Masanori Tsujimoto, Department of Neurosurgery, Gifu University Graduate School of Medicine, Yanagido, Gifu city, Gifu 501-1194, Japan; masanori-t.117@ hotmail.co.jp

Received 30 March 2016 Revised 7 June 2016 Accepted 15 June 2016 Published Online First 1 July 2016
CrossMark

To cite: Tsujimoto $\mathrm{M}$, Enomoto Y, Kokuzawa J, et al. J Neurolntervent Surg 2017:9:106-110.

\section{ABSTRACT}

Background Increased platelet reactivity after carotid artery stenting (CAS) may cause thromboembolic complications.

Objective This study aimed to investigate the incidence of increased platelet reactivity after CAS and to determine the factors related to it.

Methods Patients who underwent CAS were recruited prospectively. They received pre-procedural antiplatelet therapy comprising some combination of aspirin (100 mg/day), clopidogrel $(75 \mathrm{mg} /$ day), and/or cilostazol (200 mg/day) for a minimum of 7 days. ADP- and collagen-induced platelet aggregation were measured before and 4 days after CAS. Changes in platelet reactivity were reported as changes in the categorized platelet reactivity grade based on the effective dose $50 \%$. Clinical characteristics of patients with and without increased platelet reactivity were compared. Results Among 38 consecutive patients who underwent CAS, 18 (47\%) exhibited increased platelet reactivity. Diabetes mellitus (OR 15.0; $95 \% \mathrm{Cl} 2.1$ to 106.5; $p=0.007$ ) and carotid artery plaques exhibiting high-intensity signals (HIS) on time-of-flight MR angiography (TOF-MRA) (OR 25.2; $95 \% \mathrm{Cl} 2.0$ to $316.2 ; p=0.013$ ) were independently associated with increased platelet reactivity in a multivariate analysis. Conclusions Increased platelet reactivity occurred in nearly half of the studied patients subjected to CAS and was independently associated with diabetes mellitus and carotid artery plaques exhibiting HIS on TOF-MRA.

\section{INTRODUCTION}

Despite the designation of carotid endarterectomy (CEA) as the gold standard management for internal carotid artery stenosis according to multiple large randomized controlled clinical trials, ${ }^{1-3}$ the use of carotid artery stenting (CAS) as an appropriate alternative therapy is increasing. Two randomized controlled clinical trials of CEA and CAS have demonstrated comparable levels of procedural safety and stroke prevention efficacy, ${ }^{4}$ and other randomized controlled clinical trials have failed to reveal the non-inferiority of CAS. ${ }^{6-8}$ Ischemic events are the most common CAS-related complications, and a meta-analysis of several randomized clinical controlled trials found that the rate of ischemic stroke within 30 days was $7.0 \%$ among patients treated with CAS compared with only $3.5 \%$ among those treated with CEA. ${ }^{9}$ Accordingly, the importance of dual antiplatelet therapy as standard pretreatment has been emphasized for patients undergoing CAS. ${ }^{10-12}$

Increasing concerns regarding poor responses to antiplatelet therapy have been raised in the fields of neurovascular and cardiology. ${ }^{13-16}$ Recent reports involving the point-of-care assay have demonstrated intra-individual changes in measured platelet reactivity from before to after neurovascular stenting. ${ }^{17} 18$ Although the point-of-care assay, which uses single concentrations of specific agonists, is a fairly simple and convenient tool for detecting insufficient platelet inhibition, the induction of platelet aggregation at a fixed single concentration is a crucial issue. More appropriately, the concentration of agonist used to induce platelet aggregation should be optimized to reflect individual differences in platelet reactivity after antiplatelet therapy. ${ }^{19} 20$

Light transmittance aggregometry (LTA), which allows the use of several agonists at specific concentrations, is considered the gold standard for platelet aggregation measurement. Platelet reactivity tends to exhibit an active sigmoid dose-response curve $\mathrm{e}^{21}$ in which changes in reactivity appear as a curve shift. ${ }^{22}$ The effective dose $50 \%\left(\mathrm{ED}_{50}\right)$ is widely used to evaluate reactivity in this type of dose response; specifically, a change in the $\mathrm{ED}_{50}$ indicates a change in reactivity. Therefore, platelet aggregation should be evaluated using multiple concentrations of the agonist because the $\mathrm{ED}_{50}$ is determined based on the results of these tests.

In this study we used LTA to investigate changes in platelet reactivity from before to after CAS and identified factors related to increased platelet reactivity.

\section{METHODS}

Patients

Between October 2013 and September 2015, all patients admitted with a diagnosis of internal carotid artery stenosis and treated with CAS at the Department of Neurosurgery, Gifu University Hospital were investigated prospectively. Clinical demographic information such as age, sex, previous atherosclerosis-related history, and perioperative medical conditions was recorded. The indication criterion for CAS was stenosis $>80 \%$ in asymptomatic lesions and/or $>50 \%$ in symptomatic lesions, in accordance with the North American 
Symptomatic Carotid Endarterectomy Trial (NASCET) protocol. Patients were treated with antiplatelet therapy comprising some combination of aspirin $(100 \mathrm{mg} /$ day $)$, clopidogrel $(75 \mathrm{mg} /$ day $)$, and/or cilostazol (200 mg/day) for a minimum of 7 days before the procedure; these agents were selected at the discretion of the attending physicians. Patients continued to receive the same antiplatelet therapy for at least 3 months after CAS. The experimental protocol was approved by the institutional ethics committee and informed consent was obtained from all patients.

\section{Blood sampling and preparation of human platelet-rich plasma}

Blood samples were collected before and 4 days after CAS to avoid the effects of heparin or catecholamine, which was used during or after CAS. Blood samples were drawn into a $1 / 10$ volume of $3.2 \%$ sodium citrate. Platelet-rich plasma (PRP) was obtained from blood samples by centrifugation at $155 \mathrm{~g}$ for $12 \mathrm{~min}$ at room temperature. Platelet-poor plasma (PPP) was prepared from residual blood by centrifugation at $1400 \mathrm{~g}$ for 5 min.

\section{ADP and collagen induction of light transmittance platelet aggregation}

Aggregation of platelets in citrated PRP was conducted at $37^{\circ} \mathrm{C}$ in a light transmittance aggregometer (PA-200 Kowa, Tokyo, Japan) with a stirring speed of $800 \mathrm{rpm}$. ADP (Sigma-Aldrich, St Louis, Missouri, USA) and collagen (Takeda Austria, Linz, Austria) were used to induce aggregation. Platelets were preincubated for $1 \mathrm{~min}$; subsequently, aggregation was monitored for 4 min after the addition of the agonist. The PRP and corresponding PPP transmittance percentages were recorded as $0 \%$ and $100 \%$, respectively, and aggregation was expressed as a percentage of the maximum transmittance. Each agonist was tested at three concentrations: ADP 3, 10, and $20 \mu \mathrm{M}$ and collagen 3, 10 , and $20 \mu \mathrm{g} / \mathrm{mL}$.

The $\mathrm{ED}_{50}$ was defined as the concentration required to induce $>50 \%$ platelet aggregation transmittance; a low $\mathrm{ED}_{50}$ value indicates high platelet reactivity. We used the $\mathrm{ED}_{50}$ to classify platelet reactivity to ADP stimulation as follows: high reactivity, $\mathrm{ED}_{50} \leq 3 \mu \mathrm{M}$; medium to high reactivity, 3.1-10 $\mu \mathrm{M}$; medium to low reactivity, $10.1-20 \mu \mathrm{M}$; and low reactivity, $>20 \mu \mathrm{M}$. Similarly, reactivity to collagen stimulation was classified as follows: high reactivity, $\mathrm{ED}_{50} \leq 3 \mu \mathrm{g} / \mathrm{mL}$; medium to high reactivity, $3.1-10 \mu \mathrm{g} / \mathrm{mL}$; medium to low reactivity, $10.1-20$ $\mu \mathrm{g} / \mathrm{mL}$; and low reactivity, $>20 \mu \mathrm{g} / \mathrm{mL}$ (figure 1 ). We defined an increase in platelet reactivity as a shift to a higher reactivity category over serial assessments. Patients who exhibited increased platelet reactivity to ADP stimulation, collagen stimulation, or both were categorized as activated.

\section{MRI analysis}

All patients underwent preoperative MRI screening followed by digital subtraction angiography to ascertain the suitability of their lesions for CAS. Previous reports identified carotid artery plaques exhibiting high-intensity signals (HIS) on time-of-flight magnetic resonance angiography (TOF-MRA), as observed on sagittal oblique maximum intensity projection images, as an independent risk factor for ischemic complications in patients subjected to $\mathrm{CAS}^{23}$ We therefore recorded this sign during plaque evaluation.

In all patients, baseline diffusion-weighted imaging (DWI) was performed after diagnostic angiography and before CAS. A second DWI was performed within 72 hours after CAS, at which time only newly appearing lesions were regarded as ischemic lesions after CAS. MRI findings were evaluated by blinded neuroradiologists.

\section{CAS procedures}

All CAS procedures were performed under local anesthesia via the percutaneous transfemoral route. All procedures were performed by a single neurointerventional team. A $100 \mathrm{U} / \mathrm{kg}$ heparin bolus was administered immediately before the procedure to increase the activated clotting time to a minimum of

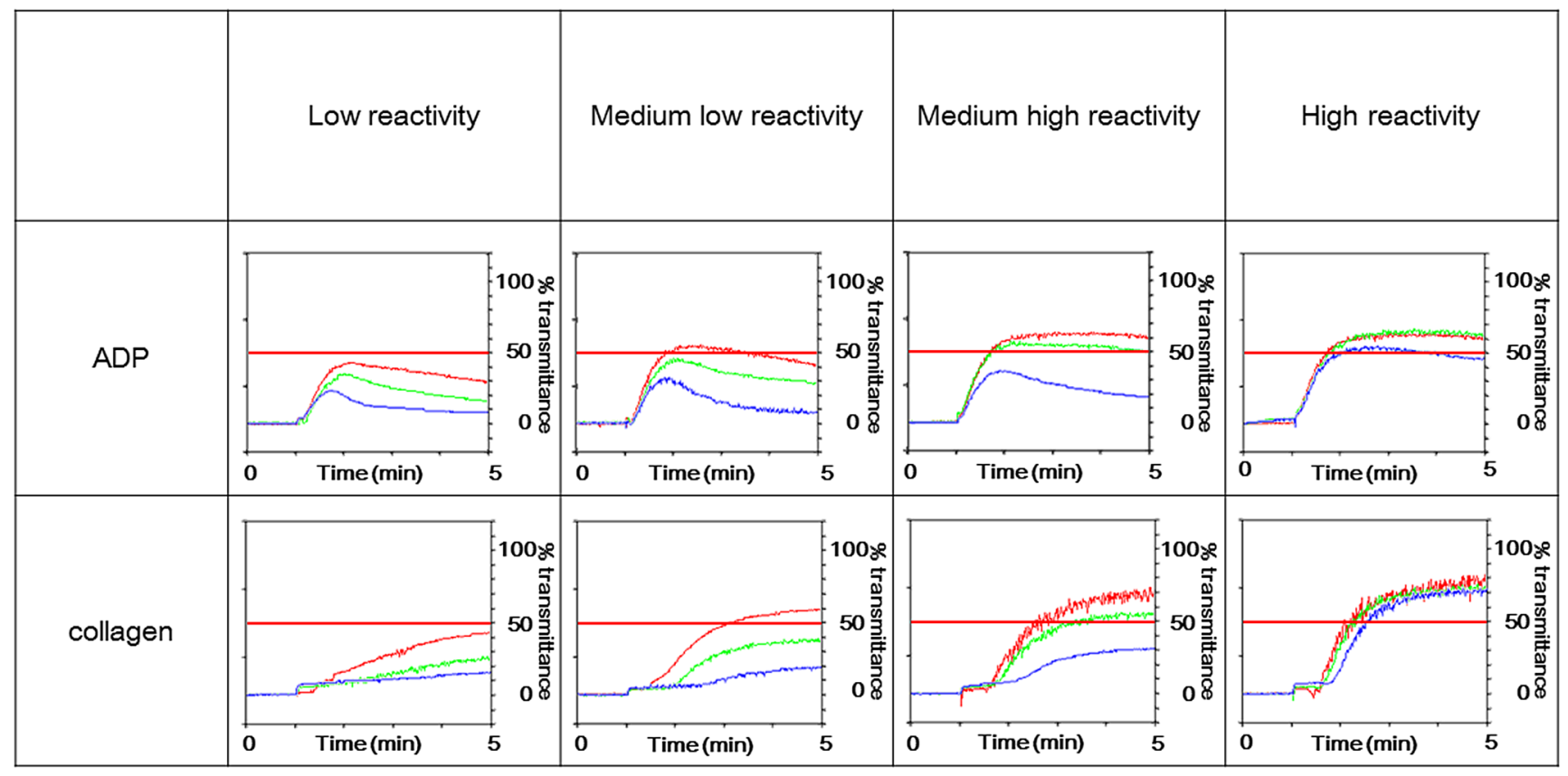

Figure 1 Platelet reactivity grade categorization based on effective dose $50 \%\left(E D_{50}\right)$ values. Representative platelet aggregation curves of each platelet reactivity grade are shown. Blue lines indicate $3 \mu \mathrm{M}$ ADP and $3 \mu \mathrm{g} / \mathrm{mL}$ collagen, green lines indicate $10 \mu \mathrm{M}$ ADP and $10 \mu \mathrm{g} / \mathrm{mL}$ collagen, and red lines indicate $20 \mu \mathrm{M}$ ADP and $20 \mu \mathrm{g} / \mathrm{mL}$ collagen. 

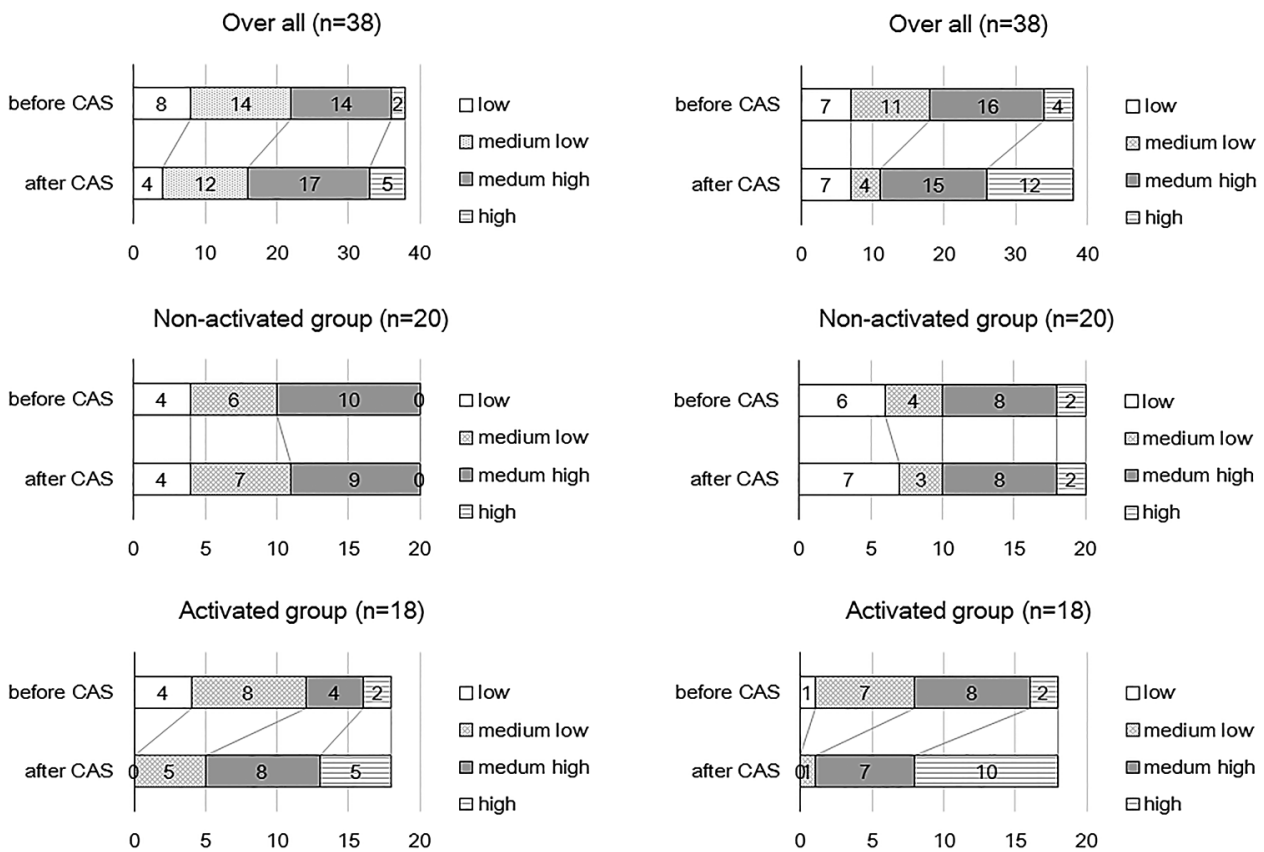

Figure 2 Distribution of categorized platelet reactivity grades based on effective dose $50 \%\left(E D_{50}\right)$ values. The numbers of patients are shown in each cell according to the platelet reactivity category. Platelet reactivity grades were classified as follows: high reactivity, $E D_{50} \leq 3 \mu \mathrm{M} ;$ medium to high reactivity, 3.1-10 $\mu \mathrm{M}$; medium to low reactivity, 10.1-20 $\mu \mathrm{M}$; and low reactivity, $>20 \mu \mathrm{M}$ for ADP stimulation $(A)$, and high reactivity, $E D_{50}$ $\leq 3 \mu \mathrm{g} / \mathrm{mL}$; medium to high reactivity, 3.1-10 $\mu \mathrm{g} / \mathrm{mL}$; medium to low reactivity, $10.1-20 \mu \mathrm{g} / \mathrm{mL}$; and low reactivity, $>20 \mu \mathrm{g} / \mathrm{mL}$ for collagen stimulation (B).

$250 \mathrm{~s}$. Two types of embolic protection devices were used: distal balloon protection via a Guardwire (Medtronic AVE, Santa Rosa, California, USA; $\mathrm{n}=16$ ) or proximal balloon protection via an Optimo (Tokai Medical Products, Aichi, Japan) and Guardwire $(n=22)$. Two types of stents were placed in the stenotic lesions: an open cell stent such as Precise (Johnson \& Johnson, Cordis, Minneapolis, Minnesota, USA; $n=32$ ) or Protage (Covidien, Mansfield, Massachusetts, USA; $n=2$ ), or a Wallstent (Boston Scientific, Natick, Massachusetts, USA; $n=4$ ) closed cell stent. Stroke neurologists performed neurological assessments 24 hours after CAS.

\section{Statistical analysis}

Values are presented as means \pm SD. Categorical variables were analyzed using the $\chi^{2}$ or Fisher's exact test as appropriate. Continuous variables with normal distributions were analyzed using the Student's t-test or the paired t-test; those with nonnormal distributions were analyzed using the Mann-Whitney $\mathrm{U}$ test or Wilcoxon signed-rank test as appropriate. Univariate and multivariate logistic regression analyses were performed to determine which factors correlated with increased platelet reactivity after CAS. A $p$ value of $<0.05$ was considered statistically significant. All statistical analyses were performed using PASW Statistics software, V.18 (SPSS Japan, Tokyo, Japan).

\section{RESULTS}

A total of 38 consecutive patients who underwent CAS during the study period were included. All procedures were successfully completed and yielded adequate angiographic results. Among the 38 patients, $20(53 \%)$ and $18(47 \%)$ were categorized as nonactivated and activated, respectively. ADP- and collagen-induced changes in categorized platelet reactivity grades are shown in figure $2 \mathrm{~A}$ and $\mathrm{B}$, respectively. The characteristics of patients in the non-activated and activated groups are shown in table 1.
Platelet reactivity before CAS did not differ significantly between the groups; in contrast, platelet reactivity after CAS was significantly higher in the activated group than in the non-activated group at all concentrations of ADP and collagen (table 2). In the univariate analysis, a significantly larger number of patients in the activated group presented with diabetes mellitus (DM) compared with the non-activated group (13/18 (72\%) vs 3/20 (15\%); $\mathrm{p}<0.001)$. The level of glycated hemoglobin $(\mathrm{HbA1c})$ was also significantly higher in the activated group than in the non-activated group $(6.5 \pm 0.7 \mathrm{mg} / \mathrm{dl}$ vs $5.9 \pm 0.7 \mathrm{mg} / \mathrm{dl} ; \mathrm{p}=0.02)$. Furthermore, HIS was observed significantly more frequently on TOF-MRA evaluations of patients in the activated group $(10 / 18 ; 56 \%)$ than in the non-activated group $(1 / 20 ; 5 \% ; \mathrm{p}=0.001)$.

After CAS, the incidence of ischemic lesions on DWI did not differ significantly between the groups $(5 / 20$ (25\%) in the nonactivated group vs $6 / 18(33 \%)$ in the activated group; $p=0.64)$. One patient in the non-activated group experienced an ipsilateral symptomatic stroke during CAS $(1 / 20 ; 5 \%)$; no symptomatic strokes occurred in the activated group $(p=0.53)$. No other thromboembolic complications occurred within 30 days after CAS in either group.

Only variables with $\mathrm{p}$ values $<0.20$ in the univariate analysis were included in the multivariate logistic regression model; these included DM, hyperlipidemia, HIS on TOF-MRA, triglyceride concentration, and HbA1c concentration. DM (OR 15.0; $95 \%$ CI 2.1 to $106.5 ; \mathrm{p}=0.007)$ and the presence of HIS on TOF-MRA (OR 25.2; 95\% CI 2.0 to 316.2 ; $\mathrm{p}=0.013$ ) were found to be independent factors related to increased platelet reactivity after CAS (table 3 ).

\section{DISCUSSION}

In this study we found that nearly half of the studied patients developed increased platelet reactivity after CAS, and that DM and the presence of carotid artery plaques exhibiting HIS on 


\section{Basic science}

Table 1 Baseline characteristics among patients in the present study subgroups

\begin{tabular}{|c|c|c|c|c|}
\hline & All $(n=38)$ & $\begin{array}{l}\text { Non-activated } \\
\text { group }(n=20)\end{array}$ & $\begin{array}{l}\text { Activated group } \\
(n=18)\end{array}$ & $\mathrm{p}$ Value \\
\hline Age, years & $71.9 \pm 8.0$ & $71.0 \pm 9.0$ & $73.0 \pm 6.8$ & 0.44 \\
\hline Male sex & $32(84)$ & $18(90)$ & $14(78)$ & 0.28 \\
\hline \multicolumn{5}{|l|}{ History } \\
\hline Diabetes mellitus & $16(42)$ & $3(15)$ & $13(72)$ & $<0.001$ \\
\hline Hypertension & $31(82)$ & $16(80)$ & $15(83)$ & 0.56 \\
\hline Hyperlipidemia & $25(66)$ & $11(55)$ & $14(78)$ & 0.14 \\
\hline Symptomatic stenosis & $17(45)$ & $9(45)$ & $8(44)$ & 0.97 \\
\hline \multicolumn{5}{|l|}{ Medication } \\
\hline Aspirin & $32(84)$ & $18(90)$ & $14(78)$ & 0.28 \\
\hline Clopidogrel & 37 (97) & $20(100)$ & $17(94)$ & 0.47 \\
\hline Cilostazole & $13(34)$ & $5(25)$ & $8(44)$ & 0.21 \\
\hline Statins & $24(63)$ & $11(55)$ & $13(72)$ & 0.27 \\
\hline \multicolumn{5}{|l|}{ Plaque evaluation MRI/MRA } \\
\hline HIS on TOF-MRA & $11(29)$ & $1(5)$ & $10(56)$ & 0.001 \\
\hline \multicolumn{5}{|l|}{ CAS procedure } \\
\hline Protection & & & & 0.7 \\
\hline Distal balloon protection & $16(42)$ & $9(45)$ & $7(39)$ & \\
\hline Proximal balloon protection & $22(58)$ & $11(55)$ & $11(61)$ & \\
\hline Stent & & & & 0.34 \\
\hline Open cell & $34(89)$ & $17(85)$ & $17(94)$ & \\
\hline Closed cell & $4(11)$ & $3(15)$ & $1(6)$ & \\
\hline Periprocedural ischemic symptoms & $1(3)$ & 1 (5) & $0(0)$ & 0.53 \\
\hline $\begin{array}{l}\text { Postoperative ischemic lesions on } \\
\text { DWI }\end{array}$ & $11(29)$ & $5(25)$ & $6(33)$ & 0.64 \\
\hline \multicolumn{5}{|l|}{ Laboratory parameters } \\
\hline Triglycerides, mg/dL & $117.0 \pm 53.5$ & $100.5 \pm 42.0$ & $134.5 \pm 60.0$ & 0.09 \\
\hline $\mathrm{HDL}$ cholesterol, mg/dL & $61.1 \pm 30.0$ & $64.3 \pm 33.9$ & $57.1 \pm 23.7$ & 0.5 \\
\hline LDL cholesterol, mg/dL & $104.2 \pm 41.7$ & $112.2 \pm 48.0$ & $93.9 \pm 30.4$ & 0.21 \\
\hline C-reactive protein, $\mathrm{mg} / \mathrm{dL}$ & $0.5 \pm 1.4$ & $0.7 \pm 1.9$ & $0.3 \pm 0.6$ & 0.34 \\
\hline Hemoglobin A1c, mg/dL & $6.2 \pm 0.8$ & $5.9 \pm 0.7$ & $6.5 \pm 0.7$ & 0.02 \\
\hline Platelets, $\times 10^{4} / \mathrm{mm}^{3}$ & $22.6 \pm 4.5$ & $22.3 \pm 4.1$ & $23.0 \pm 4.9$ & 0.72 \\
\hline
\end{tabular}

Table 2 Maximum aggregation values

\begin{tabular}{|c|c|c|c|}
\hline & $\begin{array}{l}\text { Non-activated } \\
\text { group }(n=20)\end{array}$ & $\begin{array}{l}\text { Activated group } \\
(n=18)\end{array}$ & p Value \\
\hline \multicolumn{4}{|l|}{ Before CAS } \\
\hline \multicolumn{4}{|l|}{$\mathrm{ADP}$} \\
\hline $3 \mu \mathrm{M}$ & $31.2 \pm 11.7$ & $29.7 \pm 12.8$ & 0.70 \\
\hline $10 \mu \mathrm{M}$ & $45.1 \pm 13.4$ & $44.7 \pm 12.8$ & 0.62 \\
\hline $20 \mu \mathrm{M}$ & $51.4 \pm 12.9$ & $51.9 \pm 13.6$ & 0.93 \\
\hline \multicolumn{4}{|l|}{ Collagen } \\
\hline $3 \mu \mathrm{g} / \mathrm{mL}$ & $30.9 \pm 17.4$ & $27.4 \pm 18.5$ & 0.63 \\
\hline $10 \mu \mathrm{g} / \mathrm{mL}$ & $47.9 \pm 20.9$ & $49.3 \pm 19.4$ & 0.82 \\
\hline $20 \mu \mathrm{g} / \mathrm{mL}$ & $59.1 \pm 22.4$ & $61.6 \pm 15.4$ & 0.87 \\
\hline \multicolumn{4}{|l|}{ After CAS } \\
\hline \multicolumn{4}{|l|}{ ADP } \\
\hline $3 \mu \mathrm{M}$ & $32.3 \pm 10.4$ & $41.0 \pm 14.3$ & 0.037 \\
\hline $10 \mu \mathrm{M}$ & $46.6 \pm 11.1$ & $57.5 \pm 8.5$ & 0.002 \\
\hline $20 \mu \mathrm{M}$ & $53.5 \pm 12.6$ & $63.8 \pm 8.4$ & 0.031 \\
\hline \multicolumn{4}{|l|}{ Collagen } \\
\hline $3 \mu \mathrm{g} / \mathrm{mL}$ & $30.5 \pm 17.6$ & $49.3 \pm 19.4$ & 0.003 \\
\hline $10 \mu \mathrm{g} / \mathrm{mL}$ & $48.5 \pm 19.5$ & $67.6 \pm 12.7$ & 0.001 \\
\hline $20 \mu \mathrm{g} / \mathrm{mL}$ & $61.6 \pm 18.0$ & $77.0 \pm 10.5$ & 0.022 \\
\hline
\end{tabular}

TOF-MRA were independently associated with increased platelet reactivity after CAS. To our knowledge, this study is the first to conduct an LTA-based investigation of factors associated with increased platelet reactivity after CAS.

Following the placement of a stent within a vessel, platelet-rich thrombi form in response to the foreign material. ${ }^{24}$ In addition, the exposed subendothelium-a consequence of cracking and dislodging of the plaque due to balloon angioplasty or stent deployment-interacts with platelets and induces additional thrombogenic reactions. In a previous report we noted that carotid artery plaques that exhibited HIS on TOF-MRA indicated the presence of plaques containing fragile components. ${ }^{23}$ Such plaques are at risk of rupture during CAS procedures, which could lead to increased platelet activation in the affected patients.

Among patients subjected to CAS, previously reported risk factors for stroke or death after CAS included DM and age $>75$ years ${ }^{25}$ however, the mechanism underlying these associations was not clarified. Several mechanisms have been suggested to explain the enhanced platelet function characteristic of DM, among which metabolic alterations, oxidative stress, and endothelial dysfunction appear to play crucial roles. ${ }^{26}$ In patients with DM, amplified platelet reactivity to several agonists and insufficient suppression of activated platelets consequent to endothelial dysfunction might promote platelet reactivity after CAS. Our observation of increased platelet 
Table 3 Multivariate logistic regression analysis of independent predictive factors associated with increased platelet reactivity after CAS

\begin{tabular}{llll}
\hline & OR & $95 \% \mathrm{Cl}$ & $\mathbf{p}$ Value \\
\hline Diabetes mellitus & 15.0 & 2.10 to 106.5 & 0.007 \\
HIS on TOF-MRA & 25.2 & 2.00 to 316.2 & 0.013 \\
\hline
\end{tabular}

CAS, carotid artery stenting; HIS, high-intensity signal; TOF-MRA, time-of-flight magnetic resonance angiography.

reactivity might explain the poor outcomes of patients with DM after CAS.

Several studies have reported the occurrence of thromboembolic complications both within and beyond $24 \mathrm{~h}$ after CAS, ${ }^{27} 28$ and meta-analyses of randomized controlled clinical trials have reported relatively high incidence rates of thromboembolic complications within 30 days after CAS. ${ }^{9}$ Despite improvements in the devices used to protect against embolic barrage during CAS, the prevention of post-procedural thromboembolic complications is a critical issue that should be addressed to improve the outcomes of patients undergoing CAS. Continuous intensive antiplatelet therapy during the periprocedural period, which aims to reduce the number of thromboembolic complications, is an advantage of CAS relative to CEA; however, the increased platelet reactivity associated with the former procedure might counteract this advantage.

This study has several limitations. First, this was a single-center study of a small number of patients and therefore we could not draw any definitive conclusions regarding the relationship between changes in platelet reactivity after CAS and thromboembolic events. Second, the method used to classify patients as activated or non-activated could not be used to evaluate changes in platelet reactivity in all patients because, once a patient had been categorized as highly reactive, further increases in platelet reactivity could not be identified. In the present study, no patients were categorized as highly reactive to both ADP- and collagen-induced platelet aggregation, and therefore increased platelet reactivity to at least one agonist could be determined. To resolve these limitations, future analyses should include platelet functioning tests involving multiple concentrations of multiple agonists and larger numbers of patients to ensure the accurate recognition of changes in platelet reactivity after CAS.

\section{CONCLUSIONS}

This study observed increased post-procedural platelet reactivity in nearly half of patients subjected to CAS. In addition, DM and the presence of carotid artery plaques exhibiting HIS on TOF-MRA were found to be independently associated with increased platelet reactivity after CAS.

Acknowledgements The authors thank Dr Takayuki Kato and Dr Yasuhiko Kaku for their advice on editing the manuscript.

Funding This study was supported by Grants-in-Aid for Scientific Research Grant Number 25861267 and 16K20001 from the Japan Society for the Promotion of Science.

Competing interests None declared.

Ethics approval Ethics approval was obtained from the Committee of Ethics in Gifu University Graduate School of Medicine.

Provenance and peer review Not commissioned; externally peer reviewed.

Open Access This is an Open Access article distributed in accordance with the Creative Commons Attribution Non Commercial (CC BY-NC 4.0) license, which permits others to distribute, remix, adapt, build upon this work non-commercially, and license their derivative works on different terms, provided the original work is properly cited and the use is non-commercial. See: http://creativecommons.org/licenses/by-nd/4.0/

\section{REFERENCES}

1 North American Symptomatic Carotid Endarterectomy Trial Collaborators. Beneficial effect of carotid endarterectomy in symptomatic patients with high-grade carotid stenosis. N Engl J Med 1991;325:445-53.

2 Endarterectomy for asymptomatic carotid artery stenosis. Executive Committee for the Asymptomatic Carotid Atherosclerosis Study. JAMA 1995;273:1421-8.

3 Randomised trial of endarterectomy for recently symptomatic carotid stenosis: final results of the MRC European Carotid Surgery Trial (ECST). Lancet 1998;351:1379-87.

4 Yadav JS, Wholey MH, Kuntz RE, et al. Protected carotid-artery stenting versus endarterectomy in high-risk patients. N Engl J Med 2004;351:1493-501.

5 Brott TG, Hobson RW II, Howard G, et al. Stenting versus endarterectomy for treatment of carotid-artery stenosis. N Engl J Med 2010;363:11-23.

6 Ringleb PA, Allenberg J, Bruckmann $\mathrm{H}$, et al. 30 day results from the SPACE trial of stent-protected angioplasty versus carotid endarterectomy in symptomatic patients: a randomised non-inferiority trial. Lancet 2006;368:1239-47.

7 Mas JL, Trinquart L, Leys D, et al. Endarterectomy Versus Angioplasty in Patients with Symptomatic Severe Carotid Stenosis (EVA-3S) trial: results up to 4 years from a randomised, multicentre trial. Lancet Neurol 2008;7:885-92.

8 Ederle J, Dobson J, Featherstone RL, et al. Carotid artery stenting compared with endarterectomy in patients with symptomatic carotid stenosis (International Carotid Stenting Study): an interim analysis of a randomised controlled trial. Lancet 2010;375:985-97.

9 Bonati LH, Dobson J, Algra A, et al. Short-term outcome after stenting versus endarterectomy for symptomatic carotid stenosis: a preplanned meta-analysis of individual patient data. Lancet 2010;376:1062-73.

10 McKevitt FM, Randall MS, Cleveland TJ, et al. The benefits of combined anti-platelet treatment in carotid artery stenting. Eur J Vasc Endovasc Surg 2005;29:522-7

11 Bates ER, Babb JD, Casey DE Jr, et al. ACCF/SCAI/SVMB/SIR/ASITN 2007 clinical expert consensus document on carotid stenting: a report of the American College of Cardiology Foundation Task Force on Clinical Expert Consensus Documents (ACCF) SCAI/SVMB/SIR/ASITN Clinical Expert Consensus Document Committee on Carotid Stenting). J Am Coll Cardiol 2007;49:126-70.

12 Enomoto $\mathrm{Y}$, Yoshimura S. Antiplatelet therapy for carotid artery stenting. InterV Neurol 2013;1:151-63.

13 Prabhakaran S, Wells KR, Lee VH, et al. Prevalence and risk factors for aspirin and clopidogrel resistance in cerebrovascular stenting. AJNR Am J Neuroradiol 2008;29:281-5

14 Reavey-Cantwell JF, Fox WC, Reichwage BD, et al. Factors associated with aspirin resistance in patients premedicated with aspirin and clopidogrel for endovascular neurosurgery. Neurosurgery 2009;64:890-5; discussion 895-6.

15 Aradi D, Komócsi A, Vorobcsuk A, et al. Prognostic significance of high on-clopidogrel platelet reactivity after percutaneous coronary intervention: systematic review and meta-analysis. Am Heart J 2010;160:543-51.

16 Tantry US, Bonello L, Aradi D, et al. Consensus and update on the definition of on-treatment platelet reactivity to adenosine diphosphate associated with ischemia and bleeding. J Am Coll Cardiol 2013;62:2261-73.

17 Lee DH, Kim HS, Kim SM, et al. Change of platelet reactivity to antiplatelet therapy after stenting procedure for cerebral artery stenosis: VerifyNow antiplatelet assay before and after stenting. Neurointervention 2012;7:23-6.

18 Kim BJ, Kwon JY, Jung JM, et al. Association between silent embolic cerebral infarction and continuous increase of $\mathrm{P} 2 \mathrm{Y} 12$ reaction units after neurovascular stenting. J Neurosurg 2014;121:891-8.

19 Zimmermann N, Hohlfeld T. Clinical implications of aspirin resistance. Thromb Haemost 2008;100:379-90.

20 Kunicki TJ, Williams SA, Salomon DR, et al. Genetics of platelet reactivity in normal, healthy individuals. J Thromb Haemost 2009;7:2116-22.

21 Jancinová V, Nosál R, Petríková M. Dose-response aggregometry-contribution to the precise platelet function evaluation. Thromb Res 1992;65:1-11.

22 Suttitanamongkol S, Gear AR. ADP receptor antagonists inhibit platelet aggregation induced by the chemokines SDF-1, MDC and TARC. FEBS Lett 2001;490:84-7.

23 Yoshimura S, Yamada K, Kawasaki M, et al. High-intensity signal on time-of-flight magnetic resonance angiography indicates carotid plaques at high risk for cerebral embolism during stenting. Stroke 2011;42:3132-7.

24 Schwartz RS. Pathophysiology of restenosis: interaction of thrombosis, hyperplasia, and/or remodeling. Am J Cardiol 1998;81:14E-7E.

25 Schluter M, Reimers B, Castriota F, et al. Impact of diabetes, patient age, and gender on the 30-day incidence of stroke and death in patients undergoing carotid artery stenting with embolus protection: a post-hoc subanalysis of a prospective multicenter registry. J Endovasc Ther 2007;14:271-8.

26 Ferroni P, Basili S, Falco A, et al. Platelet activation in type 2 diabetes mellitus. J Thromb Haemost 2004;2:1282-91.

27 Tan KT, Cleveland TJ, Berczi V, et al. Timing and frequency of complications after carotid artery stenting: what is the optimal period of observation? J Vasc Surg 2003;38:236-43.

28 Parlani G, De Rango P, Norgiolini L, et al. Timing of complications during carotid artery stenting. How can they be predicted? Acta Chir Belg 2006;106:367-71. 